Article

\title{
Evaluation of Alternative Annular Denuder Systems for the Collection of Fine Aerosol Particulate Matter
}

\author{
Jennifer Spencer ${ }^{1}$, Vern Osborne ${ }^{2}$ and Bill Van Heyst ${ }^{1, *}$ \\ 1 School of Engineering, University of Guelph, Guelph, ON N1G 2W1, Canada; jspencer@uoguelph.ca \\ 2 Department of Animal Biosciences, University of Guelph, Guelph, ON N1G 2W1, Canada; \\ vosborne@uoguelph.ca \\ * Correspondence: bvanheys@uoguelph.ca
}

Received: 29 November 2019; Accepted: 31 January 2020; Published: 7 February 2020

\begin{abstract}
Due to the complex manner in which secondary inorganic aerosols (SIAs) form, a need exists to develop a methodology to measure $\mathrm{PM}_{2.5}$ emissions from agricultural operations to better understand the contribution of SIAs to the $\mathrm{PM}_{2.5}$ fraction. When sampling particulate matter (PM), annular denuder systems (ADS) are a United States Environmental Protection Agency (US EPA) approved system used to measure both gaseous and particulate components of aerosols. While collecting basic gases, such as ammonia, using nine denuders was feasibly demonstrated in poultry housing units but the ability of additional denuders to accurately collect the SIAs on the filters is yet to be demonstrated. An experiment was designed to assess particle deposition behaviors throughout three different ADS configurations. It was determined that the nine denuder configuration resulted in particles being impacted and retained, mainly in the U-bend junctions, prior to reaching the filters with only $87.2 \%$ of $\mathrm{PM}_{2.5}$ reaching the filter pack. The US EPA-prescribed ADS configuration had $99.4 \%$ of $\mathrm{PM}_{2.5}$ reaching the filters, indicating that there is an impact due to the U-Bend addition to the system. It was further demonstrated that having additional denuders in series with no U-Bend had no significant impact on $\mathrm{PM}_{2.5}$ deposition on the filters with $98.9 \%$ of $\mathrm{PM}_{2.5}$ being collected.
\end{abstract}

Keywords: chloride aerosol; annular denuder system; $\mathrm{PM}_{2.5}$; secondary inorganic aerosols; and animal housing

\section{Introduction}

Air quality concerns continue to propagate globally due to their negative impacts on animal, human, and ecosystem health. Particulate matter (PM) is a specific constituent of air pollution that has increasingly garnered concern due to the growing body of scientific evidence of the impact it has on the environment and human health [1-5]. PM is broken down into categories based on the size fractions of the particles. Coarse $\mathrm{PM}\left(\mathrm{PM}_{10}\right)$ is defined as having an aerodynamic diameter equal to or less than $10 \mu \mathrm{m}$, while fine $\mathrm{PM}\left(\mathrm{PM}_{2.5}\right)$ has an aerodynamic diameter of $2.5 \mu \mathrm{m}$ and smaller. Of the two size fractions, $\mathrm{PM}_{2.5}$ is of greater concern with respect to human health effects, as the smaller diameter of the particles allows it to penetrate deeper into the lungs where it becomes difficult for the body to expel. When $\mathrm{PM}_{2.5}$ reaches the lower regions of the lungs, the particles can become embedded in the tissues of the bronchi and bronchioles. The toxins often carried with the fine particles can then diffuse into the bloodstream via the alveoli [6].

PM emissions can be further categorized as either primary or secondary based on the source and formation process of the particles. Primary particles are released directly by a source as a particle and include, for example: biomass burning emissions, diesel exhaust, and dusts from soil $[7,8]$. Secondary particles are formed in the atmosphere through chemical reactions with gases containing sulfate, nitrate, ammonia, and various organic compounds. This process is often referred to as gas-to-particle 
conversion and occurs by either condensation or direct nucleation. Condensation is the process by which mass is added onto an existing particle, and nucleation is where a precursor gas is converted into a fine aerosol [9]. The precursor gases are either acidic or basic and neutralize in the presence of each other, forming either secondary organic aerosols (SOAs) or secondary inorganic aerosols (SIAs), depending on the nature of the precursor gases. The formation of SOAs and SIAs results in aerosols that are small in diameter and typically fall within the $\mathrm{PM}_{2.5}$ size fraction.

In an animal housing and production facility, the formation of secondary aerosols is dominated by the neutralization of basic ammonia $\left(\mathrm{NH}_{3}\right)$ gas with acidic sulfur and nitrogen gases $[9,10]$. Enclosed animal production facilities, which are common in Canadian animal husbandry operations, provide an environment suitable for the generation and accumulation of ammonia and acid gases. Ammonia is produced from the microbial breakdown of the nitrogen-laden manure and excreta and, as such, is typically found in higher concentrations inside the barn or manure storage facilities than after land application outdoors or when composted [11,12]. Ammonia emissions are, however, not limited to agricultural practices alone. For example, in Canada, the mining, manufacturing, oil and gas, and power generation sectors also contribute to emissions [13].

Acid gases include sulfuric acid $\left(\mathrm{H}_{2} \mathrm{SO}_{4}\right)$, nitric acid $\left(\mathrm{HNO}_{3}\right)$, and hydrochloric acid $(\mathrm{HCl})$, all of which are transferred into the barn from the exterior [4] or are the reaction products of gases released from treated water and/or feed [14]. When $\mathrm{NH}_{3}$ reacts with any of these acid gases, it creates ammonium salts that are classified as SIAs $[14,15]$. When these gases neutralize and form aerosols, the resulting SIAs include: ammonium sulphate $\left(\left(\mathrm{NH}_{4}\right)_{2} \mathrm{SO}_{4}\right)$, ammonium bisulfate $\left(\mathrm{NH}_{4} \mathrm{HSO}_{4}\right)$, ammonium nitrate $\left(\mathrm{NH}_{4} \mathrm{NO}_{3}\right)$, and ammonium chloride $\left(\mathrm{NH}_{4} \mathrm{Cl}\right)$ [7] In poultry production, the formation mechanisms of these reactions are dependent on the environmental conditions within the animal housing unit, the exterior environmental conditions, seasonal variability, and the animal's stage of growth [14].

Concentration exposure standards and limits for PM, which are specific to air quality, vary from country to country and are set with the intention of protecting human health and reducing the impact on ecosystems [1]. The 24-h mean exposure standard for $\mathrm{PM}_{2.5}$ has been set by the World Health Organization and the European Commission at $25 \mu \mathrm{g} / \mathrm{m}^{3}[16,17]$, while in Canada and the United States the 24-h $\mathrm{PM}_{2.5}$ mean exposure concentration is currently set at $27 \mu \mathrm{g} / \mathrm{m}^{3}$ and $35 \mu \mathrm{g} / \mathrm{m}^{3}$, respectively [18-20].

While the 24-h mean exposure concentration for $\mathrm{PM}_{2.5}$ has been established by various governing bodies, the emissions of $\mathrm{PM}_{2.5}$ from animal production facilities are not restricted by regulations in Canada, Europe [21], or the US [22]. Quantifying the extent of $\mathrm{PM}_{2.5}$ emissions from agriculture can help to strengthen the overall understanding of its impact on human health and the surrounding environment. Currently, secondary $\mathrm{PM}_{2.5}$ from agricultural emission sources is not estimated by Canadian governing bodies and therefore has not been directly reported in pollution summary reports [13]. $\mathrm{PM}$ and $\mathrm{NH}_{3}$ emissions from the agriculture sector are currently determined based on monitoring data and emission factors [13]. For poultry production specifically, $\mathrm{PM}_{2.5}$ data presented in the Air Pollution Emission Inventory (APEI) report is based on emission factors developed previously [23,24]. Animal production estimates of $\mathrm{PM}_{2.5}$ from non-poultry species are determined from primary dust measurements that do not specify secondary emissions or precursor gas species. In Canada, agriculture has contributed $94 \%$ of the country's ammonia emissions according to the national pollutant emission inventories since 2017 [13,25]. If sufficient acid gases are present during the release of ammonia, there is a significant potential that the impact from the generated SIA on the $\mathrm{PM}_{2.5}$ regional and national inventories is underestimated [1]. The European Union has reported similar ammonia emission's to Canada. In 2015, it was reported that $92 \%$ of ammonia emissions across the 28 countries were from the agricultural sector [26]. From a global health perspective, the World Health Organization (WHO) estimated that a total of 4.2 million premature deaths were caused by ambient $\mathrm{PM}_{2.5}$, which is an increase from the 3.1 million deaths estimated in 2010 [5,27]. This significant increase in death signals a growing need to continually monitor and report emissions from all sources in an effort to understand source apportionment and ultimately reduce global mortalities. 
Due to the complex manner in which secondary aerosols form, there is a need to develop new, or modify existing, measurement tools for monitoring and analyzing $\mathrm{PM}_{2.5}$ emissions from barn environments with high aerosol concentrations. By doing so, a greater understanding of the formation and behavior of the generated SIAs can be developed. When sampling PM in the atmosphere, annular denuder systems (ADS) are an approved system of the United States Environmental Protection Agency (US EPA) that are used to measure aerosol contaminants. Prescribed methodologies for using the ADS apparatus are outlined by $[28,29]$. The ADS is a dual-purpose measurement device with the etched glass denuders collecting the acid and base gaseous species and the dual stage filter pack, which is located after the last denuder, collecting the fine particulates. Typically, the ADS is deployed in the ambient atmosphere where low concentrations of both the acid and base gases are expected. However, inside animal production facilities, where $\mathrm{NH}_{3}$ concentrations are typically much greater than the acid gas concentrations, the ADS apparatus needs to be modified in order to measure concentrations of both acid and base gases as well as capture $\mathrm{PM}_{2.5}$ in the dual stage filter pack. As part of an ongoing study of emissions from within poultry houses, the behavior of particulates was explored using the US EPA prescribed ADS set-up and compared to the adapted methodology established by [14]. Applications outside of this specific scope, e.g., pesticide application and its impact on the applicator [30,31], manure and compost applications [11], and emission measurements near or inside industrial facilities not related to the agriculture sector, can also benefit from this exploration.

Under the US EPA-prescribed ADS method, either two or three denuders are connected in series, followed by a dual stage filter pack, as depicted in Figure 1 below. Sampling occurs over the course of hours depending on the environment but is typically in the order of 12 to $48 \mathrm{~h}$.

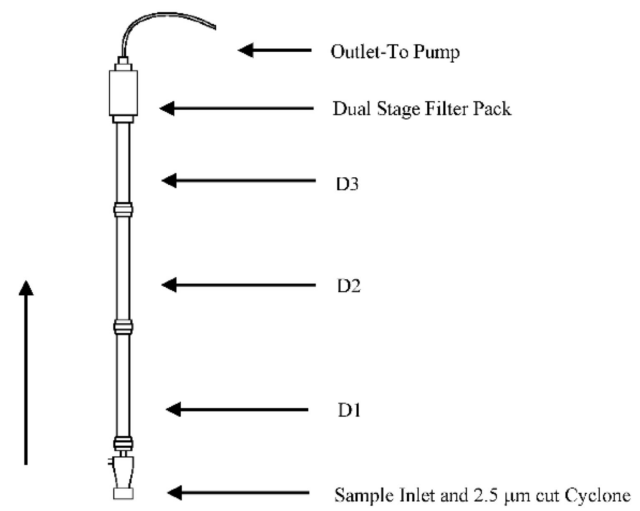

Figure 1. Three Annular Denuder System Set-Up (3-ADS), as prescribed by the United States Environmental Protection Agency (US EPA) [28,29].

Due to the high $\mathrm{NH}_{3}$ concentrations in poultry barns, which can exceed $25 \mathrm{ppm}$ (equivalent to $19 \times 10^{3} \mu \mathrm{g} / \mathrm{m}^{3}$ when converted at standard temperature and pressure), the number of denuders collecting basic gases needs to be increased while simultaneously decreasing the sampling time $[14,23,24]$. As a result, the ADS set-up and methodology presented in previous works [14] consisted of connecting nine annular denuders in series with the first two denuders coated with a basic solution to capture acid gases, followed by seven acid coated denuders to capture the elevated concentrations of $\mathrm{NH}_{3}$ and finishing with the dual stage filter pack to collect PM [14,24]. It has previously been shown that seven acid-coated denuders were required when ammonia concentrations were upwards of $25 \mathrm{ppm}$ and when using a sampling period of one hour without having any gaseous ammonia leaving the system [14]. Due to the physical length of the adapted system, four denuders were connected end-to-end followed by a Teflon U-bend connecting the next four denuders and followed by a second Teflon U-bend to connect the last denuder, followed lastly by the dual stage filter pack [14]. This allowed the ADS to be housed inside a protective cabinet during sampling inside, or adjacent to, a poultry facility. Figure 2 below depicts this adapted ADS set-up. 


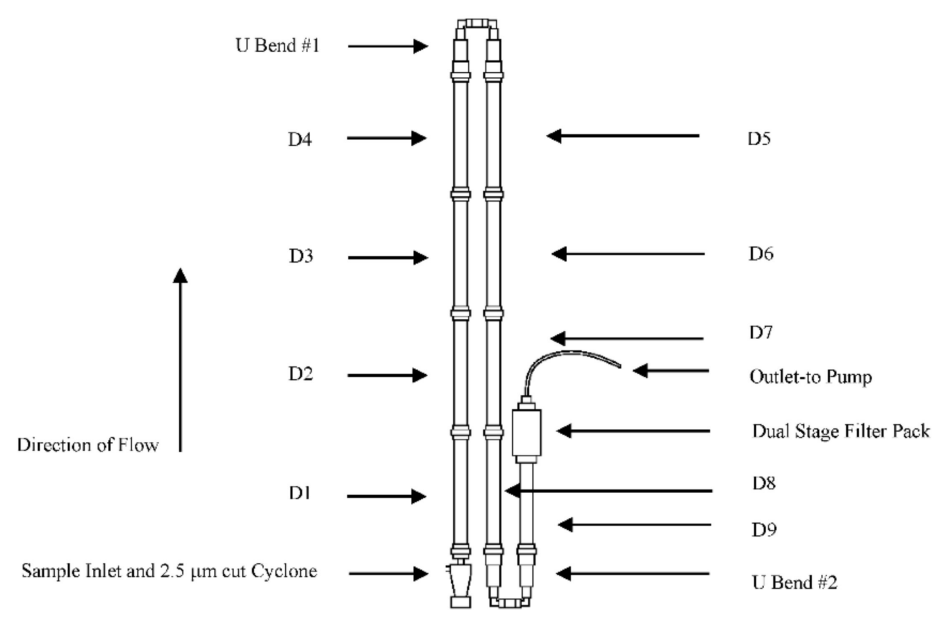

Figure 2. Nine Annular Denuder System Set-Up (9-ADS) used in previous measuring campaigns at poultry housing facilities [14].

While both modified ADS set-ups can adequately capture the acid and base gases, the issue of accurately measuring $\mathrm{PM}_{2.5}$ has not been established with more than the prescribed number of denuders in series. The US EPA prescribed methodology limits the number of denuders connected in series to two or three, as longer sampling trains allow more time for particulate matter to diffuse, absorb, and deposit onto the glass denuder walls. In the ADS set-up using the nine denuders shown in Figure 2, there is also the possibility of particles collecting in the U-bends before they reach the filter pack due to inertial impaction. Hence, the primary focus of this study was to evaluate the behavior of $\mathrm{PM}_{2.5}$ aerosols through the ADS set-ups prescribed by the US EPA (Figure 1) and in previous works (Figure 2).

\section{Materials and Methods}

To assess the behavior of $\mathrm{PM}_{2.5}$ aerosol deposition within the ADS, based on the set-up design as per Figures 1 and 2 above, an experiment was designed to assess aerosol concentration on the individual surfaces. Previous field trials using the 9-ADS sampling configuration shown above in Figure 2 demonstrated that, in poultry housing facilities, the concentration of chloride aerosols was significant when compared to sulfur and nitrate aerosols [14,32]. While $\mathrm{NH}_{3}$ gas is prevalent in and around poultry housing facilities [9-14,33-35], the presence of chloride anion aerosols were found to contribute approximately $90 \%$ of the inorganic aerosol species on average inside a broiler facility [32].

A PALAS aerosol generator (model AGK 2000) was used with the required salt solution of potassium chloride $(\mathrm{KCl})$ at a recommended concentration of $20 \%$ diluted in MilliQ water [36]. Due to the significant concentration of chloride aerosols found in poultry housing facilities [32], the $\mathrm{KCl}$ solutions required by the PALAS aerosol generator was able to act as a surrogate source of aerosols in a laboratory setting to demonstrate particulate behavior within the adapted ADS. The aerosol generator nebulizes the liquid by means of a binary atomizer nozzle. Pressure, to control the flow, is set by the user and can range between 0 and $400 \mathrm{kPa}$. For this series of experiments, the pressure was set at $250 \mathrm{kPa}$ to produce a flow rate of approximately $7 \mathrm{~L} / \mathrm{min}$. At this flow rate and salt solution concentration, the diameters of the particles generated ranged from $0.26 \mu \mathrm{m}$ to $12.41 \mu \mathrm{m}$, with $98 \%$ of the aerosols being less than $2.5 \mu \mathrm{m}$ according to particle distribution information provided by PALAS [36]. As $\mathrm{KCl}$ is neither a strong acidic nor basic solution, meaning that it is not attracted to either surface coating treatment, the aerosols would presumably not interact with the denuder walls based on the coating solution used.

The outlet of the aerosol generator was placed inside a large, custom built mixing chamber ( $0.94 \mathrm{~m}$ length by $0.42 \mathrm{~m}$ width by $0.51 \mathrm{~m}$ height), which used two internal fans to thoroughly mix the generated aerosols with incoming ambient air. Ambient air from within the lab was used to mix with 
the aerosol gas stream as there was no existing sources of particulates or pollutants. The ambient air, prior to entering the mixing chamber was passed through a HEPA filter (model Aerostar 2247, >99.97\% efficiency at $0.3 \mu \mathrm{m}$ ) to remove any ambient particles. A $3 \mathrm{~m}$ Teflon sampling line was used to draw air from the mixing chamber to the inlet of the ADS system at atmospheric pressure. The length of the sampling line was minimized as much as possible but was restricted by the physical layout of the lab space and would also mimic the general layout of an ADS taking measurements at an animal housing facility.

The procedure used for coating the denuders as well as the subsequent sampling, extraction, and analysis methods followed the US EPA Compendium Methods IP-9 and IO-4.2 [28,29]. One modification to this methodology was the use of $1 \%$ phosphorous acid solution, in lieu of the prescribed citric acid solution, to capture gaseous $\mathrm{NH}_{3}$. It was demonstrated that phosphorous acid to be more effective at neutralizing ammonia gas in high concentration environments [14]. The acid gases were captured on the denuder walls using a sodium carbonate solution as per the US EPA Compendium instructions. All ADS trials used a URG $2.5 \mu \mathrm{m}$ cut-off cyclone, located at the inlet to the ADS, to remove particles with diameters larger than the desired $2.5 \mu \mathrm{m}$.

Every ADS trial employed a dual stage filter pack at the end of the sampling train to capture the particulates. The first filter consisted of a $1 \mu \mathrm{m}$ Fluoropore Membrane Teflon Filter that collected all particles except for $\mathrm{NH}_{4} \mathrm{Cl}$ and $\mathrm{NH}_{4} \mathrm{NO}_{3}$ as these two aerosols can disassociate back into their precursor gaseous species. The second filter, a Whatman $0.8 \mu \mathrm{m}$ Nylon membrane filter, was then used to trap these two particulate species. A URG-3000-02C Mass Flow Accumulator (dry gas meter) was connected to the filter pack to measure the volume of air passing through the ADS. To complete the ADS, a URG-3000-02BAM Outdoor Sampling pump was used to draw the aerosol laden air from the mixing chamber in through the ADS and was connected to the outlet of the dry gas meter and set to a constant flow rate of $10 \mathrm{~L} / \mathrm{min}$ for the duration of each trial. Each trial conducted in the lab was done under full ambient room lighting.

Two ADS denuder configurations were evaluated for particle behavior and included: three denuders in a straight series, as prescribed by the US EPA (Figure 1) and nine denuders in series as used by [14] with two Teflon U-bends (Figure 2) To determine the effects that the U-Bends and coating treatments had on the potential to intercept particles on each surface type, each denuder configuration was tested with all denuders coated with either the acid or base coating along with a control case that used no coating on any of the denuders. Each combination of denuder train length and coating was used to measure $\mathrm{PM}_{2.5}$ concentrations in triplicate to assess variability in the results.

Sampling for each trial occurred over a one-hour period during the day inside the lab. Three trials were run during a single day grouping together the same coating type. When each trial was completed, the extractions from the denuders, filters, and U-bends (when applicable) were analyzed using a Dionex Ion Chromatograph (IC) Model ICS-2000 accompanied by a Dionex AS-40 Automated Sampler. The Anion column was a Dionex IonPac AS18 4 × 250 mm, while the Cation column was a Dionex IonPac CS16 5 × $250 \mathrm{~mm}$. During the analysis of anions, a $25 \mathrm{mM}$ potassium hydroxide eluent was used, and for cation analysis, a $30 \mathrm{mM}$ methanesulfonic acid eluent was used. All chemicals used to mix the eluent solutions were sourced from Fisher Scientific. Using a series of known ion standard dilutions, calibration curves were established to determine the identity and concentrations of ions in the extracted samples. The ion standard used for calibration was the Dionex Seven Anion Standard II solution prepared by Thermo Scientific.

While using the PALAS aerosol generator, solidified salt crystals can form on the various surfaces and inside the mixing chamber. To ensure this build-up was not causing any blockages within the sampling system, the Teflon tube, cyclone, filter casing, and inner chamber walls were checked for salt build-up after each individual trial and were cleaned if necessary. At the end of each triplicate trial (one day of sampling), all surfaces of the chamber were cleaned with deionized water and dried.

After sampling was complete, any $\mathrm{Cl}^{-}$particulates that adhered to the denuder walls and collected on the filters were extracted in preparation for analysis using the ion chromatograph. The denuder 
surfaces were extracted using $20 \mathrm{~mL}$ of MilliQ water as per the methodology developed in the previous research that was conducted [14]. The extraction fluid was then stored in individual $30 \mathrm{~mL}$ Teflon containers (one per each denuder) and refrigerated until analysis using the IC could be conducted, which was approximately 1-2 weeks after the trial was completed. Each filter was subsequently extracted following the US EPA Compendium Methods IP-9 and IO-4.2 procedure and were then stored [28,29]. As the Teflon U-Bends are not part of the standard ADS set-up, the extraction method used was similar to that used for the denuders using $20 \mathrm{~mL}$ of MilliQ water to flush any particles that were deposited on the surface of the U-bends. The rinsing fluid was then stored in individual $30 \mathrm{~mL}$ Teflon containers, refrigerated, and later analyzed using the IC as per the US EPA Compendium Methods IP-9 and IO-4.2 procedure for denuder surface extracts [28,29].

After the initial IC results were analyzed, it was determined that the $\mathrm{Cl}^{-}$concentration on the Teflon filters was greater than the standard calibration concentrations. To adjust for this, the filter extraction fluid samples were diluted to $0.1 \mathrm{~mL}$ of extraction solution into $100 \mathrm{~mL}$ of MilliQ water prior to IC analysis to obtain concentration outputs within the calibration concentration range.

When the experiments were completed, an adaptation of the two ADS designs was tested. A 5-ADS set-up, shown below in Figure 3, was subjected to the same experimental procedure to determine if adding additional denuders in series, without a Teflon U-bend, would alter the observed trends. This design was tested as it could prove to be a useful adaptation for field trials that require more than three denuders in series. Physical limitations that present themselves during field trials (ex. dimensions of cabinet used to protect the ADS both inside and outside animal housing facilities) are prohibitive to having more than 5 denuders in series without introducing an interruption to the air flow in the form of a Teflon U-bend. The number of denuders available for testing at one given time also presents a challenge when thinking ahead to field trial applications. As outlined earlier, having seven annular denuders in series is ideal for capturing ammonia at a poultry facility. However, a 7-ADS set-up in a single vertical line would not be possible in the field. Therefore, to test the impact of additional denuders in series while respecting the constraints of a field application, a 5-ADS set-up was tested. Additionally, when testing in the field using a 5-ADS set-up, the sampling time would also be reduced to prevent ammonia breakthrough in the system. The sampling time is at the control of the sampler and can therefore be adjusted.

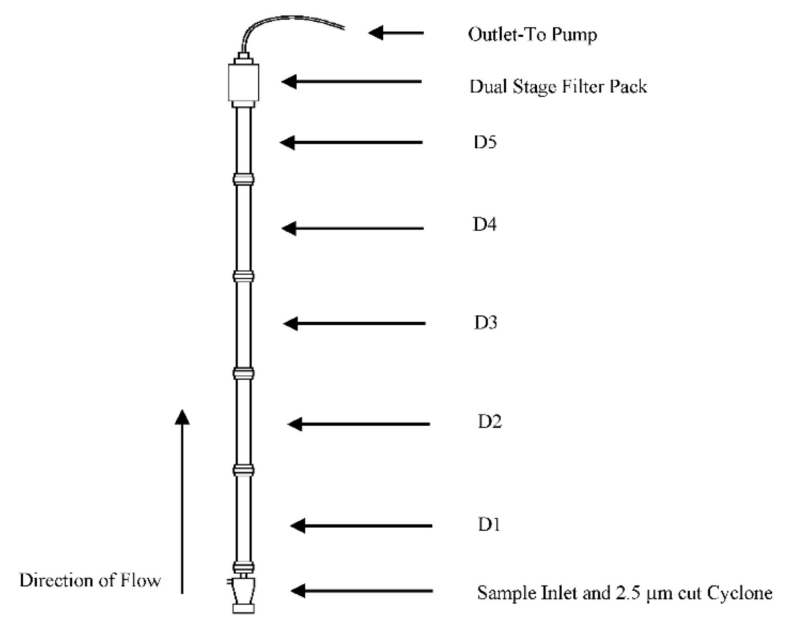

Figure 3. Five Annular Denuder System Set-Up (5-ADS).

\section{Statistical Analysis}

To compare the results between coating types, each coating treatment (acid, base, and no-coating) for each ADS set-up was subjected to a 1-h sampling run, as outlined above, three times. Once the aerosol concentration data were gathered, statistical hypothesis testing was conducted between the means of the chloride aerosol concentrations for each coating treatment. This was done by performing a 
$t$-test for two sample means using Microsoft Excel's built in data analysis tool. The $t$-test was as follows: two samples for unequal variance were used with a $95 \%$ confidence interval to compare the mean aerosol concentration of each coating treatment to determine if there was a significant difference. If the $p$-value of the $t$-test comparison proved significant $(p$-value $<0.05)$ the null hypothesis of no difference could be rejected, suggesting that the means are likely different, therefore indicating that the treatment type had an impact on the aerosol concentrations measured. Once this analysis was completed, the same procedure was used to determine if there was an impact on the aerosol concentration based on the different ADS set-up design and the system elements. The same $t$-test and confidence intervals were applied to the analysis. The version of Excel used in the analysis was Microsoft Excel for Mac, Version 16.32 (19120802) [37].

\section{Results}

Results from the analysis of $\mathrm{Cl}^{-}$concentrations following the prescribed US EPA methodology are presented in Table 1. The table outlines the percentage of $\mathrm{Cl}^{-}$collected on each system element based on the total $\mathrm{Cl}^{-}$concentration measured from the ADS as a whole. Presenting the data as a percent $\mathrm{Cl}^{-}$ collected on each surface was done in part due to the high concentrations measured on the Teflon filter and to better illustrate the average concentration of aerosol collected on each system element with respect to the system as a whole. The 3-ADS set-up shows that $\mathrm{Cl}^{-}$aerosols were found primarily on the Teflon filter for all three coating treatments. The combined percentage of the two filters shows that between $99.3 \%$ and $99.5 \%$ of the $\mathrm{Cl}^{-}$aerosol concentration was extracted from these system elements. The remaining $\mathrm{Cl}^{-}$was distributed across the three denuders, ranging from $0.519 \%$ to $0.674 \%$.

Table 1. Three-Denuder Set-up-Percent $\mathrm{Cl}^{-}$Concentrations. The values are given as the average percentage of the three trials conducted per coating treatment type (acid, base, or no coating) for a total of nine trials. The standard deviation is presented in brackets for each of the three coating types.

\begin{tabular}{cccc}
\hline System Element & $\begin{array}{c}\text { Acid Coated Denuders } \\
\mathbf{C l}^{-} \text {Concentration \% } \\
\text { (Std. Deviation) }\end{array}$ & $\begin{array}{c}\text { Base Coated Denuders } \\
\mathbf{C l}^{-} \text {Concentration \% } \\
\text { (Std. Deviation) }\end{array}$ & $\begin{array}{c}\text { No Coating on } \\
\text { Denuders } \\
\mathbf{C l}^{-} \text {Concentration \% } \\
\text { (Std. Deviation) }\end{array}$ \\
\hline D1 & $0.534(0.731)$ & $0.210(0.253)$ & $0.166(0.114)$ \\
D2 & $0.100(0.084)$ & $0.182(0.158)$ & $0.222(0.054)$ \\
D3 & $0.040(0.022)$ & $0.128(0.181)$ & $0.238(0.086)$ \\
Teflon filter & $99.1(0.975)$ & $95.3(0.513)$ & $98.3(1.01)$ \\
Nylon filter & $0.246(0.138)$ & $4.20(1.11)$ & $1.09(1.27)$ \\
Denuders & Sum of percent $\mathrm{Cl}^{-}$per System Element & 0.627 \\
Filters & 0.674 & 0.519 & 99.4 \\
\hline
\end{tabular}

The percentage of $\mathrm{Cl}^{-}$presented in Table 1 highlights the small percentage of $\mathrm{Cl}^{-}$collected within each individual denuder (D1 through D3). Figure 4 shows this information with respect to the distribution of $\mathrm{Cl}^{-}$across the three denuders by plotting the average percent concentration measured from the three denuders for the given coating type. The plot shows how the $\mathrm{Cl}^{-}$aerosols are being deposited on the denuder walls within the system before entering the dual-stage filter pack and how the coating type is possibly affecting this behavior. The standard deviations presented in Table 1 are shown as error bars for each denuder. Where the error bar moves into the negative percent range, only the positive bar has been shown. 


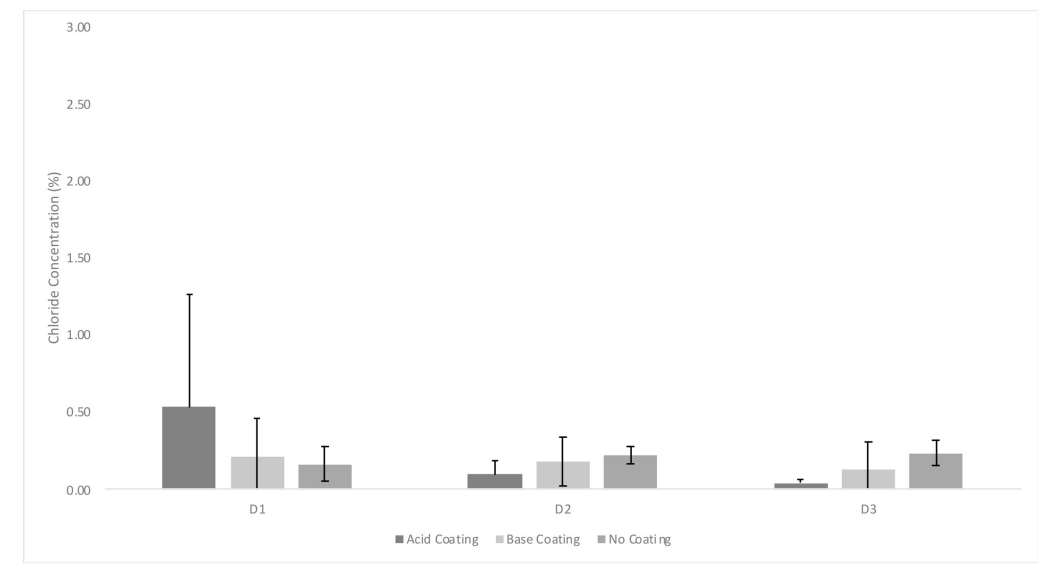

Figure 4. $\mathrm{Cl}^{-}$aerosol concentration percent on the denuder walls for the 3-ADS set-up. The values are given as the average percentage of the three trials conducted per coating type (acid, base, or no coating) for a total of nine trials.

The general trend observed in Figure 4 for the acid and base coated denuders is that D1 is subjected to higher concentrations as compared to D2 and D3. The opposite trend is observed for the denuders with no coating. However, when using the ADS according to the US EPA methodology, the denuders will have either the acid or base coating applied to the denuder walls; therefore, this trend will be of minimal concern.

After the behavior of $\mathrm{Cl}^{-}$aerosols within the 3-ADS set-up was established, a comparison was made to the methodology used in previous works at poultry housing facilities shown above in Figure 2 [14]. The results of the analysis are presented in Table 2 and Figure 5. The methodology outlined by [14] was altered for the purposes of this experiment with all nine denuders being coated with the same treatment for each series of triplicate trials (a phosphorous acid-acid coating, a sodium carbonate base coating, or no coating) to better understand particle deposition on the individual system elements, as was done for the 3-ADS set-up discussed previously.

Table 2. Average potassium chloride $(\mathrm{KCl})\left(\right.$ as $\left.\mathrm{Cl}^{-}\right)$concentration percentage of the 9-ADS set-up. The values are given as the average percentage of the three trials conducted per coating treatment type (acid, base, or no coating) for a total of nine trials. The standard deviation is presented in brackets for each of the three coating types.

\begin{tabular}{|c|c|c|c|}
\hline System Element & $\begin{array}{c}\text { Acid Coated } \\
\mathrm{Cl}^{-} \text {Concentration \% } \\
\text { (Std. Deviation) }\end{array}$ & $\begin{array}{c}\text { Base Coated } \\
\mathrm{Cl}^{-} \text {Concentration \% } \\
\text { (Std. Deviation) }\end{array}$ & $\begin{array}{c}\text { No Coating } \\
\mathrm{Cl}^{-} \text {Concentration \% } \\
\text { (Std. Deviation) }\end{array}$ \\
\hline D1 & $0.706(0.236)$ & $0.537(0.164)$ & $0.551(0.041)$ \\
\hline D2 & $0.335(0.047)$ & $0.361(0.051)$ & $0.246(0.219)$ \\
\hline D3 & $0.155(0.023)$ & $0.383(0.083)$ & $0.219(0.192)$ \\
\hline D4 & $0.154(0.023)$ & $0.353(0.029)$ & $0.439(0.175)$ \\
\hline U-Bend 1 & $3.59(0.351)$ & $6.07(0.116)$ & $4.73(0.910)$ \\
\hline D5 & $0.139(0.023)$ & $0.316(0.131)$ & $0.330(0.183)$ \\
\hline D6 & $0.270(0.010)$ & $0.307(0.032)$ & $0.370(0.121)$ \\
\hline D7 & $0.160(0.018)$ & $0.375(0.045)$ & $0.332(0.092)$ \\
\hline D8 & $0.208(0.032)$ & $0.390(0.029)$ & $0.163(0.141)$ \\
\hline U-Bend 2 & $4.19(0.864)$ & $6.68(0.293)$ & $4.72(0.771)$ \\
\hline D9 & $0.127(0.019)$ & $0.240(0.012)$ & $0.220(0.066)$ \\
\hline Teflon filter & $89.4(1.85)$ & $83.5(0.601)$ & $87.0(1.81)$ \\
\hline Nylon filter & $0.606(0.525)$ & $0.525(0.008)$ & $0.664(0.409)$ \\
\hline \multicolumn{4}{|c|}{ Sum of percent $\mathrm{Cl}^{-}$per System Element } \\
\hline Denuders & 2.25 & 3.26 & 2.87 \\
\hline U Bends & 7.79 & 12.75 & 9.45 \\
\hline Filters & 90.0 & 84.0 & 87.7 \\
\hline
\end{tabular}




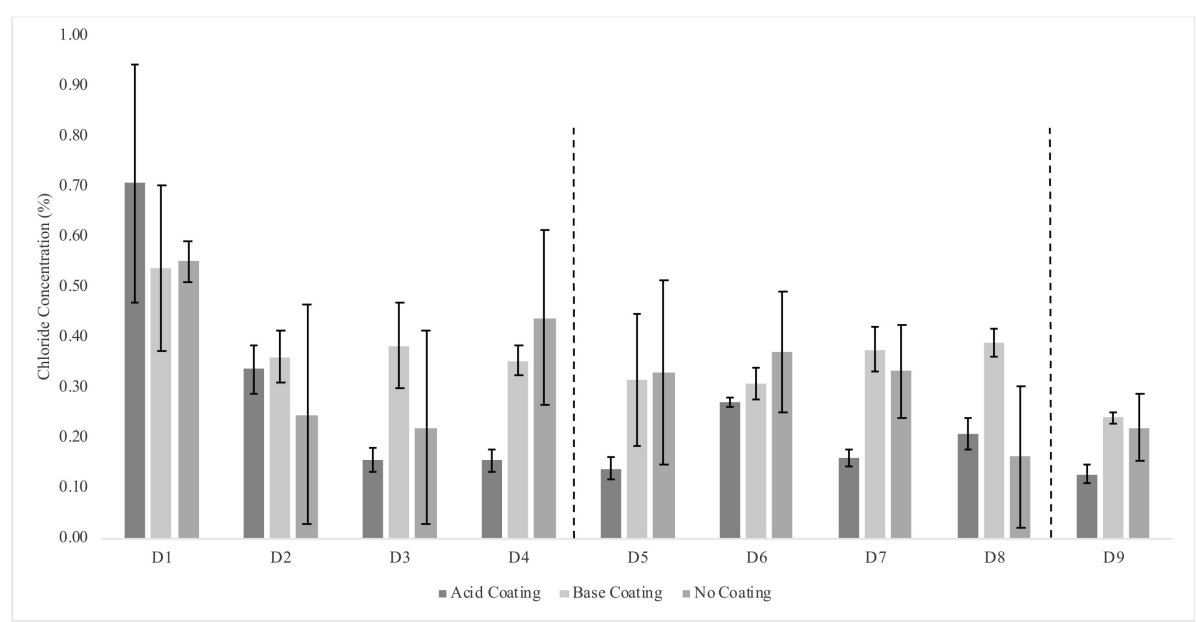

Figure 5. $\mathrm{Cl}^{-}$aerosol concentration on the denuder walls for the 9-ADS set-up. The vertical dashed lines represent the location of U-Bends in the system. The values are given as the average percentage of the three trials conducted per coating type (acid, base, or no coating) for a total of nine trials.

The percentage of $\mathrm{Cl}^{-}$presented in Table 2 similarly highlights the small percentage of $\mathrm{Cl}^{-}$collected within each individual denuder. Figure 5 shows this information with respect to the distribution of $\mathrm{Cl}^{-}$across the nine denuders, as was depicted above for the prescribed ADS set-up. The plot shows how the $\mathrm{Cl}^{-}$aerosols are being deposited on the denuder walls within the system before entering the two Teflon U-Bends and, finally, it shows the how the coating treatment type may possibly be affecting this behavior.

Upon initial review of the data in Table 2, the two Teflon U-Bends collected more $\mathrm{Cl}^{-}$aerosols as compared to the denuder walls across the three coating treatments. The filters, as expected, collected the bulk of the $\mathrm{Cl}^{-}$at $87.2 \%$ of the total on average. As with the 3-ADS set-up, the majority of $\mathrm{Cl}^{-}$ was found on the filters, however, the percentages are lower, ranging from $84.0 \%$ to $90.0 \%$. The two U-Bends collected between $7.79 \%$ and $12.75 \%$ of the $\mathrm{Cl}^{-}$aerosol and the remaining being found on the denuder surfaces. The denuders collected between $2.25 \%$ and $3.26 \%$ of the $\mathrm{Cl}^{-}$aerosol. As with the 3-ADS set-up, there was a greater concentration of $\mathrm{Cl}^{-}$found on D1 as compared to the remaining denuders and a general decrease in concentration that can be observed in Figure 5. Having the two U-Bends located within the ADS set-up and an additional six denuders in series reduced the $\mathrm{Cl}^{-}$ concentration found on the filter surfaces by $12.2 \%$ on average.

In Figure 5, the overall observed trend is that $\mathrm{Cl}^{-}$concentration on the denuder walls is highest for the first denuder but then fluctuates in magnitude in the following denuders, with the last denuder having the smallest fraction collected. It is also apparent that the acid coating on the first denuder in Figure 5 is removing a larger percentage of aerosols as compared to the other coating treatments and the remaining acid-coated denuders (D2 to D9), as was similarly found with the 3-ADS set-up. The location of the two U-bends is indicated by the dashed vertical lines in Figure 5 and indicates where the flow path is re-directed 180 degrees through them. It was demonstrated that the U-bends are collecting more $\mathrm{Cl}^{-}$aerosols as compared to the denuder walls with an average difference of $7.20 \%$.

The results from the $\mathrm{Cl}^{-}$aerosol concentration deposition on the proposed adapted 5-ADS set-up are presented in Table 3 and Figure 6. 
Table 3. Five Denuder Set-up-Percent $\mathrm{Cl}^{-}$Concentrations. The values are given as the average percentage of the three trials conducted per coating treatment type (acid, base, or no coating) for a total of nine trials. The standard deviation is presented in brackets for each of the three coating types.

\begin{tabular}{cccc}
\hline System Element & $\begin{array}{c}\text { Acid Coated Denuders } \\
\text { Cl- Concentration \% } \\
\text { (Std. Deviation) }\end{array}$ & $\begin{array}{c}\text { Base Coated Denuders } \\
\text { C- } \text { - Concentration \% }_{\text {(Std. Deviation) }}\end{array}$ & $\begin{array}{c}\text { No Coating on } \\
\text { Denuders } \\
\text { Cl- Concentration \% } \\
\text { (Std. Deviation) }\end{array}$ \\
\hline D1 & $1.14(1.79)$ & $0.735(0.180)$ & $0.234(0.194)$ \\
D2 & $0.058(0.095)$ & $0.137(0.027)$ & $0.080(0.024)$ \\
D3 & $0.040(0.057)$ & $0.133(0.019)$ & $0.088(0.023)$ \\
D4 & $0.025(0.026)$ & $0.113(0.010)$ & $0.081(0.023)$ \\
D5 & $0.048(0.048)$ & $0.142(0.034)$ & $0.089(0.016)$ \\
Teflon filter & $98.2(2.08)$ & $98.7(0.236)$ & $99.3(0.227)$ \\
Nylon filter & $0.523(0.171)$ & $0.057(0.030)$ & $0.126(0.061)$ \\
Denuders & Sum of percent $\mathrm{Cl}^{-}$per System Element & \\
Filters & 1.31 & 1.26 & 0.572 \\
& 98.7 & 98.7 & 99.4 \\
\hline
\end{tabular}

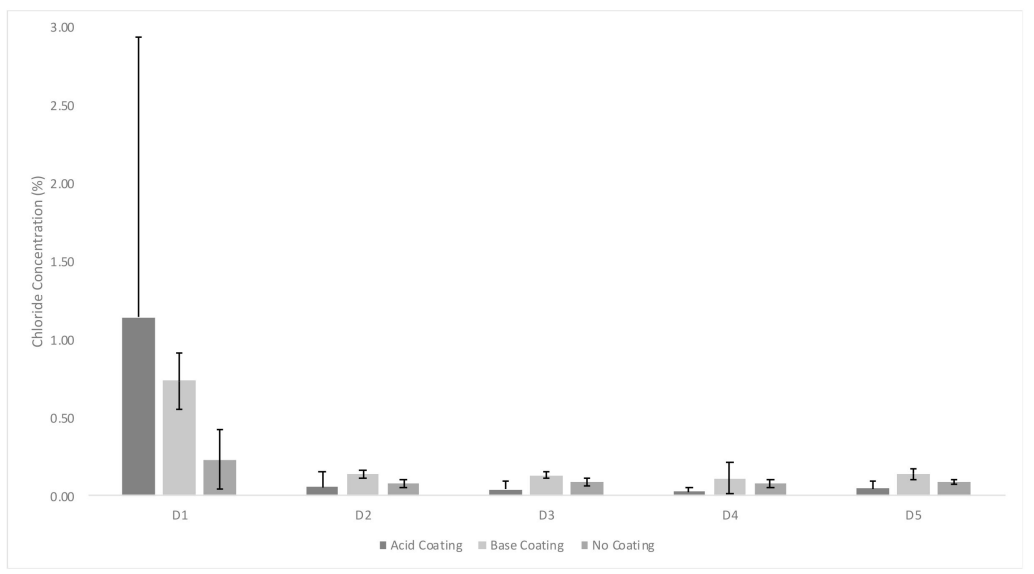

Figure 6. $\mathrm{Cl}^{-}$aerosol concentration on the denuder walls for the 5-ADS set-up. Values are given as the average percentage of the three trials conducted per coating type (acid, base, or no coating) for a total of nine trials.

The percentage of $\mathrm{Cl}^{-}$presented in Table 3 shows the small percentage of $\mathrm{Cl}^{-}$collected within each individual denuder, as was similarly found with the 3-ADS set-up. Figure 6 shows how the $\mathrm{Cl}^{-}$ concentration across the five denuders is distributed.

The trends observed using the 5-ADS configuration show similarities with what was observed for the 3-ADS configuration presented previously. The average $\mathrm{Cl}^{-}$concentration, as a percentage, found on the filters ranged from $98.7 \%$ to $99.4 \%$, with the remaining found on the denuders. Similar trends with $\mathrm{Cl}$ - aerosol deposition across the five denuders was observed in Figure 6 as compared to the 3-ADS set-up shown in Figure 4.

To compare the concentration percentages found on all three set-up designs (3-ADS, 9-ADS, and 5-ADS), the statistical analysis described above in the Methods section was performed looking at the chloride concentrations found on the denuder surfaces. Table 4 shows the resulting two-tailed $p$-values from the $t$-tests that were performed to compare two samples with unequal variances and a $95 \%$ confidence interval. 
Table 4. Statistical Analysis of Coating Treatment per ADS Set-Up alternatives. The $p$-values for the $t$-tests comparing the mean values of percent concentrations on denuder surfaces between coating treatment types with unequal variances and a $95 \%$ confidence interval. The degrees of freedom are shown in brackets.

\begin{tabular}{cccc}
\hline ADS Set-Up (Denuders) & $\begin{array}{c}\text { Acid Coating vs. Base } \\
\text { Coating }\end{array}$ & $\begin{array}{c}\text { Base Coating vs. } \\
\text { No Coating }\end{array}$ & $\begin{array}{c}\text { Acid Coating vs. } \\
\text { No Coating }\end{array}$ \\
\hline 3-ADS & $0.77(2)$ & $0.33(4)$ & $0.93(2)$ \\
9-ADS & $0.12(11)$ & $0.39(14)$ & $0.37(14)$ \\
5-ADS & $0.96(6)$ & $0.33(4)$ & $0.93(2)$ \\
\hline
\end{tabular}

Based on the results presented in Table 4, there were no significant results indicating that the concentration means on the denuder surfaces are not likely to be different due to the coating treatment type with respect to each individual ADS set-up. This information therefore allows an overall average to be used to compare the percent concentrations for each system element across the three design alternatives. The same $t$-tests comparing the mean values of unequal variances with a $95 \%$ confidence interval were conducted. Table 5 indicates the resulting $p$-values obtained from this analysis.

Table 5. Statistical Analysis comparing the Chloride aerosol percent concentrations per system element of the three ADS set-ups. The $p$-values for the $t$-tests for unequal variances, two-tailed, and the $95 \%$ confidence interval are shown. The degrees of freedom are shown in brackets.

\begin{tabular}{cccc}
\hline ADS Element & 3 ADS vs.5 ADS & 3 ADS vs. 9 ADS & 5 ADS vs.9 ADS \\
\hline Filters & $0.21(2)$ & $0.02(2)$ & $0.02(2)$ \\
Denuders & $0.21(2)$ & $0.02(2)$ & $0.01(4)$ \\
\hline
\end{tabular}

The results presented in Table 5 demonstrate significant results indicating that the concentration means on the denuder surfaces are likely to be different due to ADS set-up design. Specifically, the results show that when comparing the system elements based on design set-up, the 9-ADS set-up does appear to have an impact on the aerosol concentration percentage. This is due to the U-Bends and additional denuders in the 9-ADS set-up. This information indicates that there is an impact on aerosol concentration based on the previous 9-ADS design used for gathering data at poultry facilities [14]. However, there does not appear to be an impact of adding additional denuders in series to the US EPA prescribed ADS set-up as there was no significance in the results comparing the 3-ADS and 5-ADS set-ups, both of which do not have U-Bends.

To further explore the behavior of particle deposition on the denuder walls in the 9-ADS configuration, a $20 \% \mathrm{KBr}$ solution was then used in the PALAS aerosol generator and while replicating the experimental procedure used previously with the $\mathrm{KCl}$ solution. While the bromide salt solution is not recommended for use in the PALAS aerosol generator, the bromide anion is one that can be readily identified and measured using the IC with available standards for calibration and was therefore used to infer any differences in behavior that may be attributed to the specific aerosol species. The $\mathrm{Br}^{-}$ percent concentration and distribution across the 9-ADS set-up is shown in Table 6.

The behavior of the $\mathrm{Br}^{-}$aerosol shows a difference in the results as compared to the $\mathrm{Cl}^{-}$and $\mathrm{Br}^{-}$ion concentrations on the different system element surfaces. The bulk of particle deposition still occurred on the Teflon filter and the two U-bends for both salts. However, the remaining ion deposition on the denuder walls varies between the two aerosols. To better visualize the results, the percent accumulation outlined in Table 6 is presented in Figure 7. This graph shows the percentage of ion concentration measured on each denuder surface of the total collected on the denuder wall surfaces for the three different coating treatments. 
Table 6. Average $\mathrm{KBr}\left(\right.$ as $\left.\mathrm{Br}^{-}\right)$concentration percentage of the 9-ADS set-up. The values are given as the average percentage of the three trials conducted per coating treatment type (acid, base, or no coating) for a total of nine trials. The standard deviation is presented in brackets for each of the three coating types.

\begin{tabular}{cccc}
\hline System Element & $\begin{array}{c}\text { Acid Coated } \\
\text { Br- Concentration } \% \\
\text { (Std. Deviation) }\end{array}$ & $\begin{array}{c}\text { Base Coated } \\
\text { Br- Concentration \% } \\
\text { (Std. Deviation) }\end{array}$ & $\begin{array}{c}\text { No Coating } \\
\text { Br- Concentration \% } \\
\text { (Std. Deviation) }\end{array}$ \\
\hline D1 & $0.116(0.017)$ & $0.214(0.061)$ & $0.151(0.018)$ \\
D2 & $0.115(0.014)$ & $0.211(0.085)$ & $0.139(0.011)$ \\
D3 & $0.142(0.042)$ & $0.122(0.079)$ & $0.137(0.010)$ \\
D4 & $0.145(0.027)$ & $0.206(0.021)$ & $0.149(0.020)$ \\
U-Bend 1 & $2.70(0.230)$ & $3.32(0.728)$ & $2.46(0.065)$ \\
D5 & $0.120(0.006)$ & $0.169(0.011)$ & $0.120(0.019)$ \\
D6 & $0.114(0.006)$ & $0.152(0.032)$ & $0.140(0.016)$ \\
D7 & $0.116(0.015)$ & $0.178(0.020)$ & $0.122(0.014)$ \\
D8 & $0.141(0.021)$ & $0.215(0.035)$ & $0.152(0.017)$ \\
U-Bend 2 & $2.92(0.009)$ & $4.09(0.989)$ & $2.97(0.087)$ \\
D9 & $0.100(0.007)$ & $0.162(0.007)$ & $0.096(0.016)$ \\
Teflon filter & $93.2(0.321)$ & $90.9(1.93)$ & $93.3(0.125)$ \\
Nylon filter & $0.080(0.068)$ & $0.071(0.022)$ & $0.043(0.043)$ \\
Denuders & Sum of percent Br $r^{-}$per System Element & 1.21 \\
U Bends & 1.11 & 1.63 & 5.43 \\
Filters & 5.62 & 7.40 & 93.3 \\
\hline
\end{tabular}

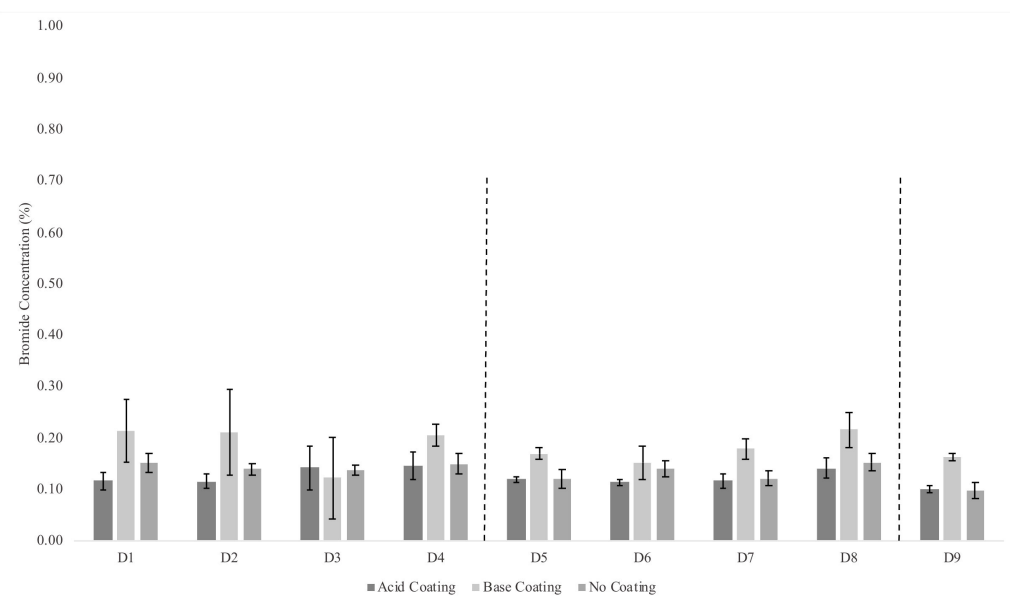

Figure 7. $\mathrm{Br}^{-}$aerosol concentration on the denuder walls for the 9-ADS set-up. The values are given as the average percentage of the three trials conducted per coating type (acid, base, or no coating) for a total of nine trials.

The overall percent $\mathrm{Br}^{-}$concentration measured on the denuder walls was less than what was found when using the $\mathrm{Cl}^{-}$solution, and the overall trend of $\mathrm{Br}^{-}$deposition across the denuders is more consistent than what was observed with the $\mathrm{Cl}^{-}$aerosol shown in Figure 5. The same statistical analysis comparing means between the coating type was also conducted for the $\mathrm{Br}^{-}$concentrations trials and found that there was significance between the acid and base coating samples, and between the base and no coating samples ( $p$-values $>0.05$ ). This suggests that the interaction of the $\mathrm{Br}^{-}$aerosol with the denuder walls coated in the basic solution has a possible impact on the concentrations as compared to the other surfaces.

It was observed with the $\mathrm{Cl}^{-}$aerosol that the concentrations across the nine denuders decreased from D1 to D9, with the highest concentration being found on the first denuder. This trend was not as 
apparent for the $\mathrm{Br}^{-}$aerosol. The reason for the different behaviors of the aerosol salts ( $\mathrm{KCl}$ vs. $\mathrm{KBr}$ ) is not readily known, however, as the aerosols are being formed from electrolyte solutions, the possibility for coagulation due to an electrical charge between particles and the coating solutions is possible but was not measured or assessed in this experiment. It was previously demonstrated that the behavior of $\mathrm{KCl}$ aerosols with respect to the relationship between charge and ion concentration for this type of aerosol is as follows: the aerosol's charge increased as the ion concentration increased [38]. This could indicate that particle charge is playing a role in the $\mathrm{KCl}$ aerosol behavior that differentiates it from the $\mathrm{KBr}$ aerosol. However, it is not known how $\mathrm{KBr}$ behaves as an aerosol with respect to its charge and concentration to determine if this is having an impact.

\section{Conclusions}

In conclusion, it was determined that, compared to the prescribed US EPA 3-ADS set-up methodology, the 9-ADS set-up did significantly impact the collection of aerosol particles on the filter surfaces. The difference in concentration of particles measured on the filters was, on average, $12.2 \%$. The impact of coating type was not significant on the particle collection on the denuder surfaces for each ADS configuration. While the 9-ADS set-up established previously [14] is effective at capturing the vast majority of particles on the filter surfaces, it does have the drawback of underestimating the total aerosol gas and particulate concentrations due to the two Teflon U-Bends. It was further determined that adding two additional denuders in series (5-ADS) to the prescribed US EPA 3-ADS configuration had no significant impact on the collection of particles on the filters. In future, it is feasible to consider testing SIA concentrations in high chloride and ammonia concentration facilities, such as poultry production facilities, using additional denuders in series, so long as there are no flow obstructions in the ADS sample pathway. While the actual in-field conditions that the 9-ADS set-up would be subjected to inside an animal housing facility will vary from those generated in the lab with respect to the aerosol chemical speciation and concentration, it is expected that the 9-ADS set-up will be underestimating the total aerosol concentration measured on the filters. Therefore, it is recommended that a field trial be conducted using the 5-ADS in an environment such as a poultry housing facility to determine the validity of this system. Further to this experiment, it is recommended that additional experiments be conducted to explore the extent of the behavioral difference between the $\mathrm{KCl}$ and $\mathrm{KBr}$ aerosols in the ADS set-ups.

Author Contributions: Conceptualization: J.S., B.V.H.; data curation: J.S., B.V.H.; data analysis: J.S., V.O., B.V.H.; funding acquisition: B.V.H.; methodology: J.S., V.O., B.V.H.; supervision: V.O., B.V.H.; writing—original draft: J.S., B.V.H.; writing - review and editing: J.S., V.O., B.V.H. All authors have read and agreed to the published version of the manuscript.

Funding: The authors would like to acknowledge all organizations that provided funding for this research. Funding was provided by the Ontario Ministry of Agriculture, Food, and Rural Affairs (OMAFRA), the Canadian Poultry Research Council (CPRC), and the University of Guelph's School of Engineering. The APC was covered as part of a feature paper invited by a guest editor.

Conflicts of Interest: The authors declare no conflict of interest.

\section{References}

1. Spencer, J.; Van Heyst, B. A review of particulate matter emissions and impacts on human health: A focus on Canadian agricultural and rural emission sources. Can. Biosyst. Eng. 2019, 2060, 6.9-6.21. [CrossRef]

2. Crouse, D.L.; Peters, P.A.; Van Donkelaar, A.; Goldberg, M.S.; Villeneuve, P.J.; Brion, O.; Khan, S.; Atari, D.O.; Jerrett, M.; Pope, I.I.I.; et al. Risk of non-accidental and cardiovascular mortality in relation to long-term exposure to low concentrations of fine particulate matter: A Canadian national-level cohort study. Environ. Health Perspect. 2012, 120, 708-714. [CrossRef] [PubMed]

3. Brook, R.D.; Cakmak, S.; Turner, M.C.; Brook, J.R.; Crouse, D.L.; Peters, P.A.; Van Donkelaar, A.; Villeneuve, P.J.; Brion, O.; Jerrett, M.; et al. Long-term fine particulate matter exposure and mortality from diabetes in Canada. Diabetes Care 2013, 36, 3313-3320. [CrossRef] 
4. Weichenthal, S.A.; Villeneuve, P.J.; Burnett, R.T.; Van Donkelaar, A.; Martin, R.V.; Jones, R.R.; DellaValle, C.T.; Sandler, D.P.; Ward, M.H.; Hoppin, J.A. Long-term exposure to fine particulate matter: Association with nonaccidental and cardiovascular mortality in the agricultural health study cohort. Environ. Health Perspect. 2014, 122, 609-615. [CrossRef]

5. World Health Organization. Health Effects of Particulate Matter Policy Implications for Countries in Eastern Europe, Caucasus and Central Asia; World Health Organization, Regional Office for Europe: Copenhagen, Denmark, 2013.

6. Canadian Centre for Occupational and Health Safety. How do Particulates Enter the Respiratory System. Available online: http://www.ccohs.ca/oshanswers/chemicals/how_do.html (accessed on 10 October 2018).

7. Bari, M.A.; Kindzierski, W.B. Fine particulate matter $\left(\mathrm{PM}_{2.5}\right)$ in Edmonton, Canada: Source apportionment and potential risk for human health. Environ. Pollut. 2016, 218, 219-229. [CrossRef]

8. Pattey, E.; Qiu, G. Trends in primary particulate matter emissions from Canadian agriculture. J. Air Waste Manag. Assoc. 2012, 62, 737-747. [CrossRef]

9. Baek, B.H.; Aneja, V.P. Measurement and analysis of the relationship between ammonia, acid gases, and fine particles in eastern North Carolina. J. Air Waste Manag. Assoc. 2004, 54, 623-633. [CrossRef]

10. Aneja, V.; Wang, B.; Tong, D.Q. Characterization of major chemical components of fine particulate matter in North Carolina. J. Air Waste Manag. Assoc. 2006, 56, 1099-1107. [CrossRef]

11. Bolan, N.S.; Szogi, A.A.; Chuasavathi, T.; Seshadri, B.; Rothrock Jr, M.J.; Panneerselvam, P. Uses and management of poultry litter. World's Poult. Sci. J. 2010, 66, 673-698. [CrossRef]

12. Pampuro, N.; Dinuccio, E.; Balsari, P.; Cavallo, E. Evaluation of two composting strategies for making pig slurry solid fraction suitable for pelletizing. Atmos. Pollut. Res. 2016, 7, 288-293. [CrossRef]

13. Environment and Climate Change Canada. Environment and Climate Change Canada. In Canada's Air Pollutant Emissions Inventory Report 1990-2017; Cat. No.: En81-30E-PDF; Environment and Climate Change Canada: Gatineau, Quebec, Canada; ISSN 2562-4903. Available online: http://publications.gc.ca/collections/ collection_2019/eccc/En81-30-2017-eng.pdf (accessed on 20 November 2019).

14. Roumeliotis, T.S.; Dixon, B.J.; Van Heyst, B.J. An annular denuder system for the collection of elevated quantities of ammonia to allow for the measurement of inorganic reactive gases and aerosol species inside poultry houses. Biosyst. Eng. 2010, 107, 178-185. [CrossRef]

15. Behera, S.N.; Sharma, M. Investigating the potential role of ammonia in ion chemistry of fine particulate matter formation for an urban environment. Sci. Total Environ. 2010, 408, 3569-3575. [CrossRef] [PubMed]

16. World Health Organization. WHO Air Quality Guidelines for Particulate Matter, Ozone, Nitrogen Dioxide and Sulfur Dioxide: Global Update 2005, Summary of Risk Assessment; World Health Organization: Geneva, Switzerland, 2006.

17. European Commission. Environment: Air Quality Standards. 2017. Available online: http://ec.europa.eu/ environment/air/quality/standards.htm (accessed on 23 November 2018).

18. Environment and Climate Change Canada. Canadian Ambient Air Quality Standards, Environment Canada and Climate Change. Available online: http://www.ec.gc.ca/default.asp?lang=En\&n=56D4043B-1\&news= A4B2C28A-2DFB-4BF4-8777-ADF29B4360BD (accessed on 18 June 2018).

19. United States Environmental Protection Agency. Criteria Air Pollutants: NAAQS (National Ambient Air Quality Standards) Table (a). Available online: https://www.epa.gov/criteria-air-pollutants/naaqs-table (accessed on 18 June 2018).

20. United States Environmental Protection Agency. Particulate Matter (PM) Basics. Available online: https: //www.epa.gov/pm-pollution/particulate-matter-pm-basics (accessed on 18 June 2018).

21. Giannakis, E.; Kushta, J.; Giannadaki, D.; Georgiou, G.K.; Bruggeman, A.; Lelieveld, J. Exploring the economy-wide effects of agriculture on air quality and health: Evidence from Europe. Sci. Total Environ. 2019, 663, 889-900. [CrossRef] [PubMed]

22. United States Environmental Protection Agency. Laws and Regulations that Apply to Your Agricultural Operations by Statute. Available online: https://www.epa.gov/agriculture/laws-and-regulations-apply-youragricultural-operation-statute\#CAA (accessed on 15 May 2019).

23. Van Heyst, B.J. Final Report: Evaluation of Emission Factors for the Improvement of the Estimation Methodology for Particulate Matter from Agricultural Poultry Industry; Report No. K2361-04-0016; University of Guelph: Guelph, ON, Canada, 2005. 
24. Roumeliotis, T.S.; Van Heyst, B.J. Size fractionated particle matter emissions from a broiler house in southern Ontario, Canada. Sci. Total Environ. 2007, 383, 174-182. [CrossRef] [PubMed]

25. Environment and Climate Change Canada. Air Pollutant Emission Inventory Report. In Environment and Climate Change Canada 1990-2016; Catalogue No.: En81-26E-PDF; Environment and Climate Change Canada: Gatineau, Quebec, Canada; ISSN 2369-940X. Available online: https://www.canada.ca/content/dam/eccc/ images/apei/apei-2018-en.pdf (accessed on 10 June 2019).

26. European Environment Agency. European Union Emission Inventory Report 1990-2017; EEA Report No. 08/2019; European Environment Agency: Copenhagen, Denmark, 2019; ISSN 1977-8449.

27. World Health Organization. Ambient (Outdoor) Air Pollution Fact Sheet. 2018. Available online: https: //www.who.int/en/news-room/fact-sheets/detail/ambient-(outdoor)-air-quality-and-health (accessed on 3 January 2020).

28. United States Environmental Protection Agency. Compendium Method IO-4.2: Determination of Reactive Acidic and Basic Gases and Strong Acidity of Atmospheric Fine Particles $((<2.5 \mu \mathrm{m})$; Center for Environmental Research Information, Office of Research and Development: Cincinnati, OH, USA, 1999.

29. Winberry, W.T.; Forehand, L.; Murphy, N.T.; Ceroli, A.; Phinney, B.; Evans, A. Compendium of Methods for the Determination of Air Pollutants in Indoor Air: Compendium Method IP-9: Annular Denuder Systems; Atmospheric Research and Exposure Assessment Laboratory, Office of Research and Development US EPA, Research: Triangle Park, NC, USA, 1990.

30. Cavallo, E. Effectiveness of agricultural tractors cabs for protection against hazardous substances in accordance with EN 15695 Part I. In Proceedings of the XVIIth World Congress of the International Commission of Agricultural and Biosystems Engineering (CIGR). CSBE1510, Québec, BC, Canada, 13-17 June 2010.

31. Di Filippo, P.; Pomata, D.; Riccardi, C.; Buiarelli, F.; De Gennaro, M.; Console, C.; Laurendi, V.; Puri, D. Determination of Pesticides in the Respirable Fraction of Airborne Particulate Matter by High-performance Liquid Chromatography-Tandem Mass Spectrometry. Anal. Lett. 2018, 51, 600-612. [CrossRef]

32. Roumeliotis, T.S.; Dixon, B.J.; Van Heyst, B.J. Characterization of gaseous pollutant and particulate matter emission rates from a commercial broiler operation part I: Observed trends in emissions. Atmos. Environ. 2010, 44, 3770-3777. [CrossRef]

33. Roumeliotis, T.S.; Dixon, B.J.; Van Heyst, B.J. Investigating a Relationship between Ammonia and Particulate Matter in Poultry Houses II: Secondary Inorganic Aerosol Formation. Paper No. 096616. In Proceedings of the ASABE Meeting, Grand Sierra Resort Reno, Nevada, UISA, 21-24 June 2009.

34. Wilson, S.M.; Serre, M.L. Examination of atmospheric ammonia levels near hog CAFOs, homes, and schools in Eastern North Carolina. Atmos. Environ. 2007, 41, 4977-4987. [CrossRef]

35. Robarge, W.P.; Walker, J.T.; McCulloch, R.B.; Murray, G. Atmospheric concentrations of ammonia and ammonium at an agricultural site in the southeast United States. Atmos. Environ. 2002, 36, 1661-1674. [CrossRef]

36. PALAS GmbH. PALAS Model AGK 2000 Operating Manual; Palas GmbH: Karlsruhe, Germany, 2015.

37. Microsoft. Microsoft Office 365; Excel Information; Microsoft Excel for Mac. Version 16.32 (19120802); Microsoft: Redmond, DC, USA, 2019.

38. Forsyth, B.; Liu, B.Y.H.; Romay, F.J. Particle charge distribution measurement for commonly generated laboratory aerosols. Aerosol Sci. Technol. 1998, 28, 489-501. [CrossRef]

(C) 2020 by the authors. Licensee MDPI, Basel, Switzerland. This article is an open access article distributed under the terms and conditions of the Creative Commons Attribution (CC BY) license (http://creativecommons.org/licenses/by/4.0/). 